\title{
Response: Commentary: Energetic particle forcing of the Northern Hemisphere winter stratosphere: comparison to solar irradiance forcing
}

\author{
Annika Seppälä ${ }^{1 *}$ and Mark A. Clilverd ${ }^{2}$ \\ ${ }^{1}$ Earth Observation, Finnish Meteorological Institute, Helsinki, Finland, ${ }^{2}$ British Antarctic Survey (NERC), Cambridge, UK
}

Keywords: energetic particle precipitation, stratosphere, dynamics, solar cycle, solar variability

\section{A commentary on}

OPEN ACCESS

Edited by:

Eugene V. Rozanov,

Physikalisch-Meteorologisches

Observatorium Davos and World

Radiation Center, Switzerland

Reviewed by:

Andreas Josef Gerhard Baumgaertner.

University of Colorado, USA

*Correspondence:

Annika Seppälä,

annika.seppala@fmi.fi

Specialty section:

This article was submitted to Atmospheric Science,

a section of the journa

Frontiers in Physics

Received: 14 August 2015

Accepted: 20 August 2015

Published: 02 September 2015

Citation:

Seppälä A and Clilverd MA (2015)

Response: Commentary: Energetic

particle forcing of the Northern

Hemisphere winter stratosphere:

comparison to solar irradiance forcing.

Front. Phys. 3:69.

doi: 10.3389/fphy.2015.00069
Commentary: Energetic particle forcing of the Northern Hemisphere winter stratosphere: comparison to solar irradiance forcing

by Tomikawa, Y. (2015). Front. Phys. 3:68. doi: 10.3389/fphy.2015.00068

We would like to thank the authors of the commentary [1] for pointing out the error in the analysis of the early winter months (Oct-Dec) in our article. We find that this is indeed correct, and wish to apologize for such an error in our analysis. After correcting the error we have been able to reproduce Figure 1 from the commentary. We wish to point out that we have checked that this issue has not affected our previous papers using re-analysis [e.g., 2]. The second issue raised concerning the inclusion of stratospheric sudden warmings (SSW) in the climatology when calculating anomalies was previously brought to our attention and discussed in the recent Conference on Sun-Climate Connections, organized in Kiel on the 16-19 March, 2015. To address this potentially significant effect in the results, we have re-analyzed the composite differences for the cases considered in our article, taking into account both the issues of SSWs and the correction for the month order.

Figure 1 presents the composite differences for "Solar Maximum-Solar Minimum" and "high Energetic Particle Forcing (EPF)-Solar Maximum." The years are as in Seppälä and Clilverd [3], but now assuring that all months are consecutive (i.e., 10, 11, 12, 1,2). These composite differences indicate that, relative to Solar maximum conditions, high EPF is able to influence the stratospheric polar night jet from early winter (Nov) onwards, with a stronger/polewards shifted polar night jet persisting throughout the winter, at first present in the upper stratosphere and later extending across the whole polar stratosphere. These latest results support the conclusions of our original article.

As before, we want to emphasize the potential effects on these signals from other factors such as the quasi-biennial oscillation, which we are not able to fully exclude due to the length of the dataset. Therefore, as soon as a full description of EPF becomes available, these potential dynamical signals should be investigated with the means of whole atmosphere chemistry-climate modeling. 


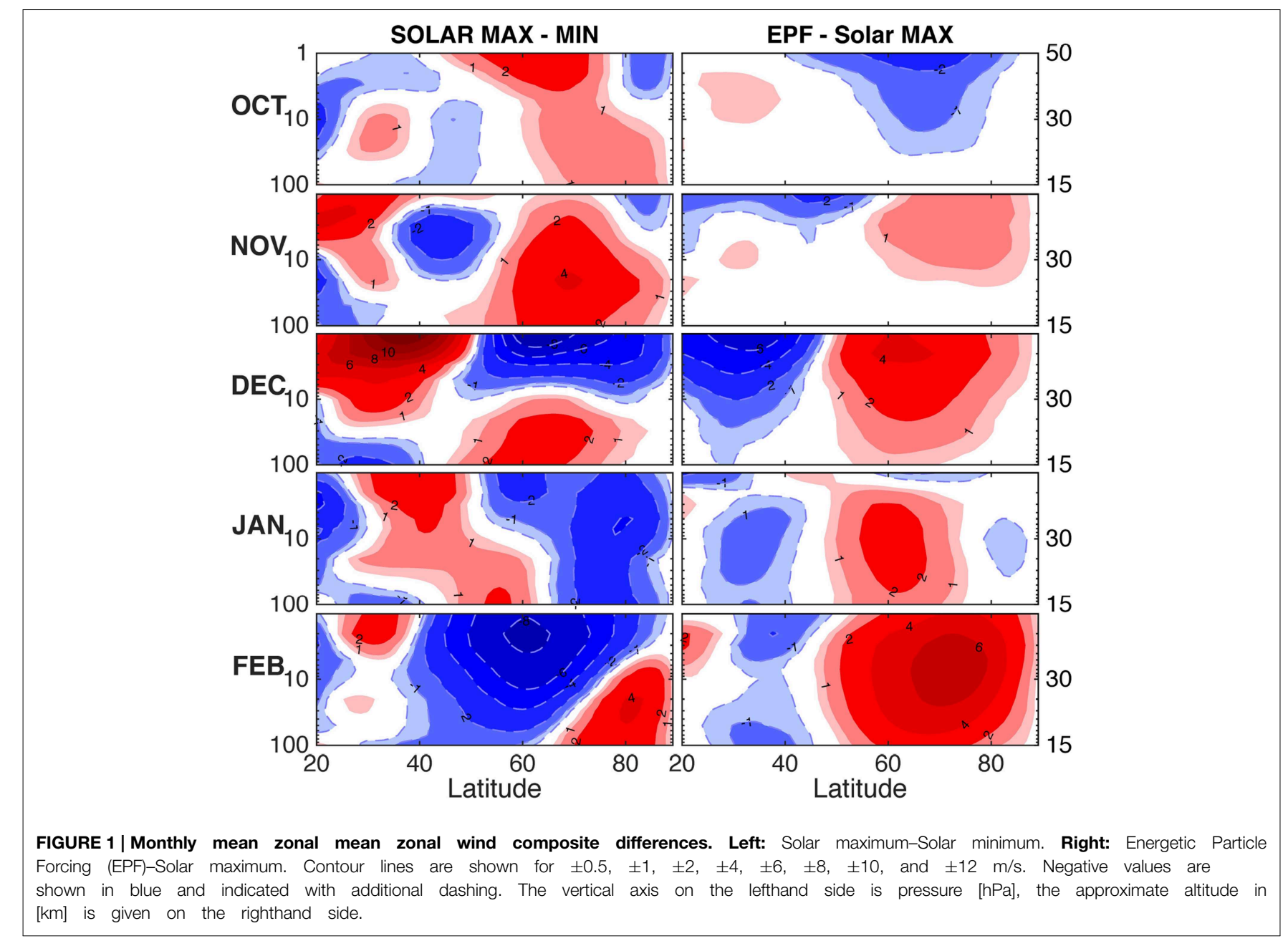

\section{Funding}

AS was supported by the Academy of Finland (Grants 258165 and 265005).

\section{References}

1. Tomikawa Y. Commentary: Energetic particle forcing of the Northern Hemisphere winter stratosphere: comparison to solar irradiance forcing. Front Phys. (2015) 3:68. doi: 10.3389/fphy.2015.00068

2. Seppälä A, Lu H, Clilverd MA, Rodger CJ. Geomagnetic activity signatures in winter time stratosphere wind, temperature, and wave response. J Geophys Res. (2013) 118:2169-83. doi: 10.1002/jgrd.50236

3. Seppälä A, Clilverd MA. Energetic particle forcing of the Northern Hemisphere winter stratosphere: comparison to solar irradiance forcing. Front Phys. (2014) 2:25. doi: 10.3389/fphy.2014.00025

\section{Acknowledgments}

The ERA-40 and ERA-Interim data are provided by ECMWF and were made available to this study by FMI and BAS/NERC.

Conflict of Interest Statement: The authors declare that the research was conducted in the absence of any commercial or financial relationships that could be construed as a potential conflict of interest.

Copyright $\odot 2015$ Seppälä and Clilverd. This is an open-access article distributed under the terms of the Creative Commons Attribution License (CC BY). The use, distribution or reproduction in other forums is permitted, provided the original author(s) or licensor are credited and that the original publication in this journal is cited, in accordance with accepted academic practice. No use, distribution or reproduction is permitted which does not comply with these terms. 